\title{
Extended Supply-Use Tables
}

\section{Introduction}

Recent technological advancements, decreasing trade costs, accessible resources and markets, reformed trade policies make the international fragmentation of production possible. This phenomenal emergence urges to improve our understanding about conventional gross trade statistics. Nowadays a finish product crosses international borders multiple times in terms of its parts and components before going to the final consumption. Therefore, we need to account value added along the production process rather than the double counted gross trade data. There are some initiatives at the international organisational level to measure trade based on value added, such as OECD-WTO TiVA, WIOD, APEC-TIVA, and European FIGARO.

Trade in value added data show the transition path of generated values from sources to destinations with respect to industries and countries. In this context, roles of MNEs are highly significant from buyer side as well as seller side. MNEs' transnational presence make them move their production processes from one economic region to another impacting almost all economic statistics. Although the gains from globalized production may not be equal across all sphere of our economy, we must strive towards inclusive globalization.

The usual statistical compilation tools and accounting frameworks advanced significantly in the last several decades to capture the degree of globalization and its impacts. But these frameworks are not so clear about accounting how much gains accrue to which section of our society in the recent scenario of production fragmentation. This realization of new accounting framework is developing the new areas of statistics of FDI measures and inwards and outwards of foreign affiliates. The recent focus on linking trade and business registers is also noteworthy. These advancements are clarifying our overall understanding of trade and investment.

However, the recent statistical developments are still in the mode of partial solution to the challenges of accounting international fragmentation of production. Because many countries have very limited relation with conventional SNA framework for compilation and collection. As a result, differences may arise between the separate collections of actual measures of the activities and the implicit equivalent core estimates of GDP. In case of FATS data, the statistical information accumulates through different exercise but those firms are in the part of GDP estimation. In some cases, replication problem (with respect to the source data) is there even if the adjustments are in the GDP accounting framework giving an inconsistent picture of published data of GDP and FATS.

We need to accurately represent the globalization in the core statistical framework rather than relegates its role to the rest of the world sector. It is necessary to consider accounts of foreign affiliates and affiliates abroad, trade across different categories of firms, and the transactionallevel trade data. Moreover, to consider inclusive globalization, we also need information of skills, occupation, and compensation for different categories of workers. Those statistics are mostly available in different surveys. It makes them inconsistent with each other.

Despite all inconsistency issues regarding data collection, the progress of TiVA-type statistics is a step-forward in this domain. The main foundation of TiVA estimates is the construction of global input-output table with some proportionality assumptions. As the construction process 
requires national Supply-Use and Input-Output tables, TiVA estimates cannot reflect firm heterogeneities resulting downward biased globalization measures.

The emerging international fragmentation of production aggravates the heterogeneity issues within sectors. The consequential hyper-specialization makes the firms to specialize in specific tasks in the production processes having very connected with imports and exports. This trend of trade in tasks leads to some producers factoryless and processors. However, recent changes in accounting framework have weaken the case of homogeneity issues.

The typical approach to represent firm heterogeneity is to use disaggregated industrial classification system. It requires burden of processing and may not be optimal for reducing heterogeneity within groupings. It may not be purposeful for analyzing production, but it highlights other approaches to consider and tackle heterogeneity. In this respect, as the supplyuse table balances the GDP estimates across income, expenditure, and production sources, it can be helpful for TiVA estimates. The extended version of SUTs can bring global measure at the national heart through a single integrated accounting framework.

\section{Extended SUTs}

The SNA 2008 presents the Supply-Use tables that distinguish production based on market output, non-market output and production for own-final use. This breakdown utilises the readily available data in most countries. This type of breakdown is very informative for additional details, granular policies, and coherent accounts. Besides this, additional details of labour inputs as hours worked, gross capital formation, and closing stocks of fixed assets give some points to analyze people with productivity measures. Despite the importance of those statistics, currently very few countries provide all this additional information. Nevertheless, very simple development is possible built on the existing presentation in administrative sources and surveys.

There are three main concerns to point out in SNA 2008. First concern is the different number of rows (products) and columns (industry, or activity groupings) in the SUT. The splits of activities into different categories of firms cannot replicate as additional splits of corresponding products by source category of producer. Second concern is the degree of splitting activities. Not all activities necessarily split because of economic reasons. The third concern from the SNA presentation concern the principle to pursue granularity in a manner that is instructive, cost effective and feasible.

\section{Simple extension}

There are some simple extensions of the supply-use tables to advance our ability to analyze and understand globalization. The simplest one is to showing separate estimates of goods for processing transactions and re-exports. They are important for TiVA calculations and to improve significantly the coherence of global supply-use tables. Differentiation between processing and non-processing production even enhances the information. Processing transactions of goods are also helpful to show the value of those imported goods whose ownership has not changed and the full customs value of goods go for exporting. Similarly, it 
is also useful to show separately the value of merchanting with gross values of exports of goods, as the process of production is significantly different.

A second set of extensions is slightly more complicated because of its less availability at the detailed product level in supply-use tables. It is the estimates of residents' expenditure abroad non-residents' expenditure. The conventional supply-use tables show these items separately to total imports and total exports with corresponding adjustments made to household final consumption. Tourism satellite accounts often provide a good basis for creating such breakdowns by product. But many countries add these items as additional rows in national supply-use tables. So, it is meaningful to add those items as complementary columns. However, there are some applications for separate breakdowns. We can better understand the tourism industry and policy making for TiVA involving tariffs. This is important to note that TiVA may likely to overestimate the multiplicative impact of cascading tariffs along a GVC if we cannot separate tourism trade in goods where tariffs do not apply typically.

A third set of extensions is about the valuation of impots. Generally, record of transactions of imported goods are in CIF prices. But global supply-use tables require a common valuation of imports and exports, implying to record import values in FOB prices. A split of imports of goods into an FOB component and a CIF component is highly desirable. Besides this, construction of import flow matrices of complementary information on tariffs/duties is also beneficial to analyze the impacts of tariffs on global value chains. Countries use survey estimates or administrative sources with proportionality assumptions to derive import flow matrices. The calculation is possible at the most detailed product level. We can break down these tables by partner or at least major partners or regional groupings. In simple case we can apply a proportionality assumption but the more refined estimates are possible through linking trade and statistical business registers at the firm level. 
Figure 1: Simple Extensions (complements) to SUTS
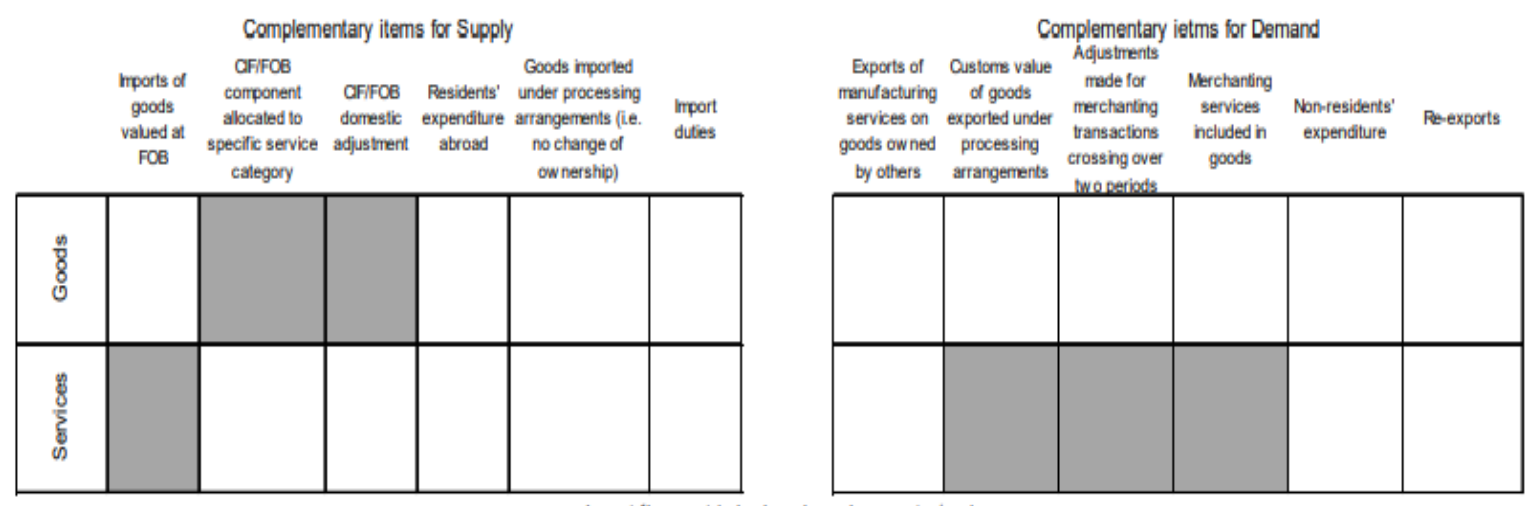

Import flow matrix broken dow $\mathrm{n}$ by country/region

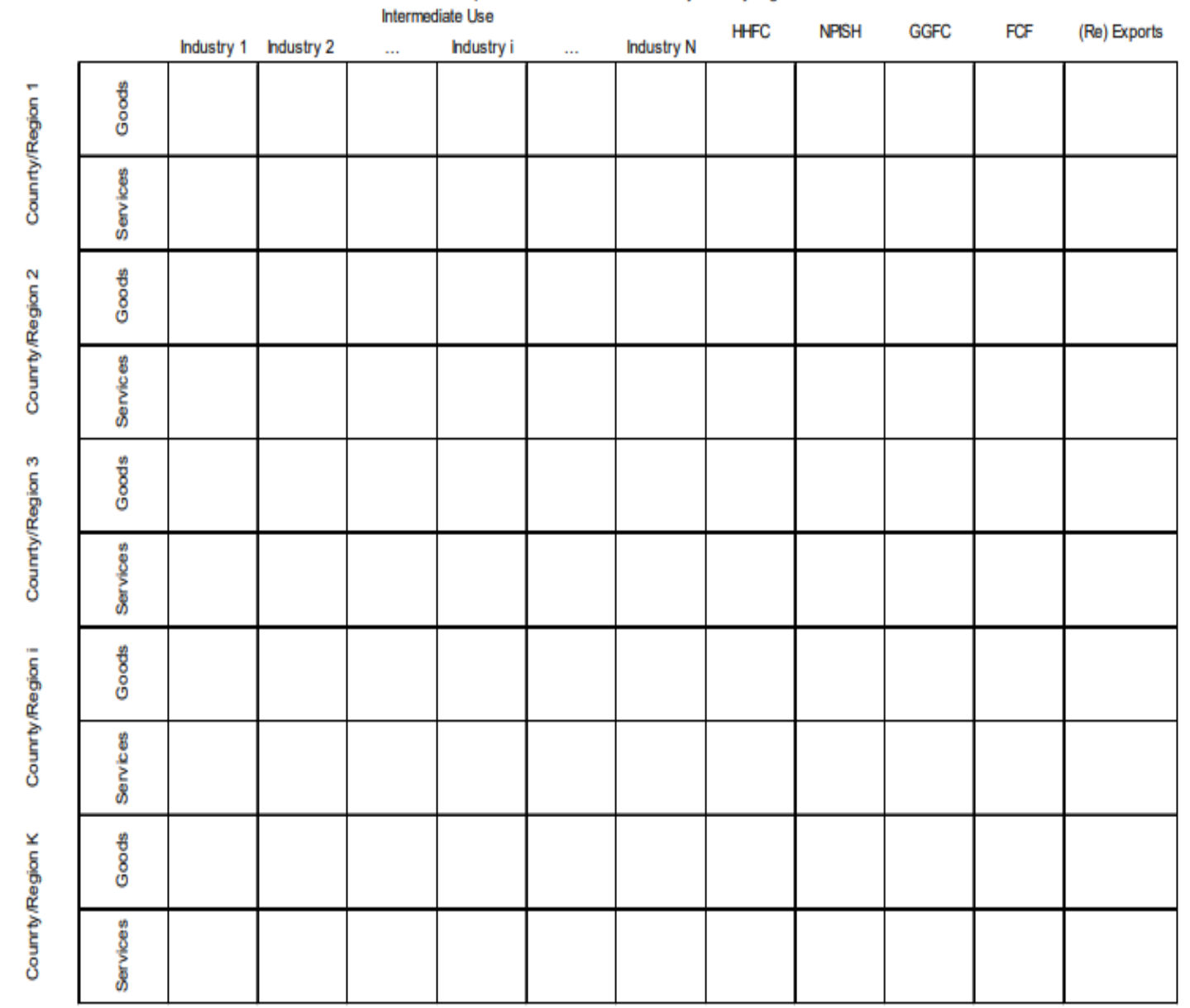

Note in the above that the reference to 'CIF/FOB domestic adjustment' refers explicitly to the adjustment made in conventional supply use tables to adjust for the transportation and insurance services provided by resident producers. These expenditures should in theory be removed from the total value of imports to ensure that total imports are valued at FOB prices. Typically, this adjustment is included as a separate row in most countries national supply-use tables (with a corresponding adjustment made to exports). The column referred to as ' $\mathrm{CIF} / \mathrm{FOB}$ domestic adjustment' therefore reflects only the allocation of this component to specific service categories. Note that this is also described in the 2008 SNA but very few countries provide this information by product. 


\section{Extensions within Activities}

The concept of breaking down activities into more homogenous or policy relevant groupings is not new. The 2008 SNA describes breakdowns between market and non-market activities and many satellite accounting systems also embody this principle. The approach in this paper is to aggregate firms and splits of activities into those that best respond to the growing demands of globalization. Of course, how countries develop extended SUTs that meet the statistical challenges of globalization necessarily depends on national circumstances. The statistical capacity is the main driver, but they should also reflect national policy demands.

The 2014 OECD Expert Group on Extended Supply-Use Tables focuses on three broad approaches possible for execution, in theory, by all countries with varying degrees of complexity. The three approaches of breakdowns are by size-class of firm (statistical unit), by trading status (exporter, importer, two-way trader, non-trader), and by ownership status (foreign owned affiliates, domestic multinational with affiliates abroad, domestic firms with no foreign affiliates). Expert group also considers combinations of above three breakdowns and alternative approaches for better reflection of national circumstances. Conceptually the breakdown of activities into heterogeneous and policy relevant grouping of firms is relatively trivial to illustrate. It requires breaking down existing activities into new and meaningful disaggregation.

Figure 2: Extended Supply-Use Tables (Activity breakdown)

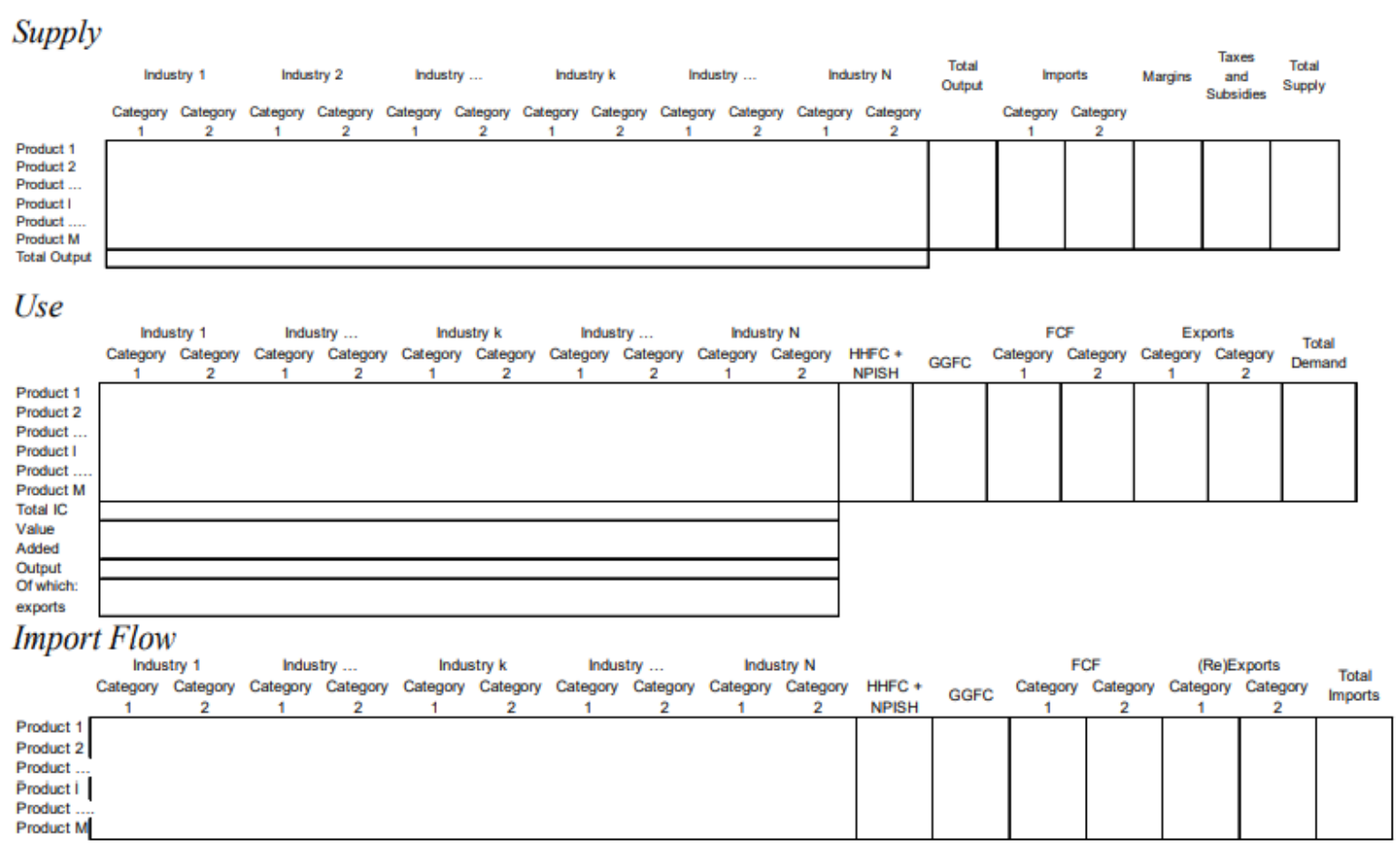

A simple illustration of an Extended supply-use table with two categories of firm. Note the inclusion of additional breakdowns of fixed capital investment, exports, and imports by the relevant categories of firms and the additional row under output, showing the exported output value. Besides this, imports of goods under processing arrangements, exports of manufacturing 
services on goods with change of ownership, customs value of goods exported under processing arrangements, and adjustments for merchanting transactions crossing over two periods.

One additional extension is of the geographical breakdown of exports. Standard indicators on GVCs derived via TiVA are not able to track the true underlying granularity implicit in the value chains. Foreign owned affiliates seem more likely to have stronger trade relationships (imports and exports) with their parent's resident country than independent firms when considering the whole value chain. This can make significant differences to trade relationships derived from TiVA measures where the averaging effect tends to weaken the strength of those ties.

Figure 3: Extended Supply-Use Tables (Activity breakdown) for Exports

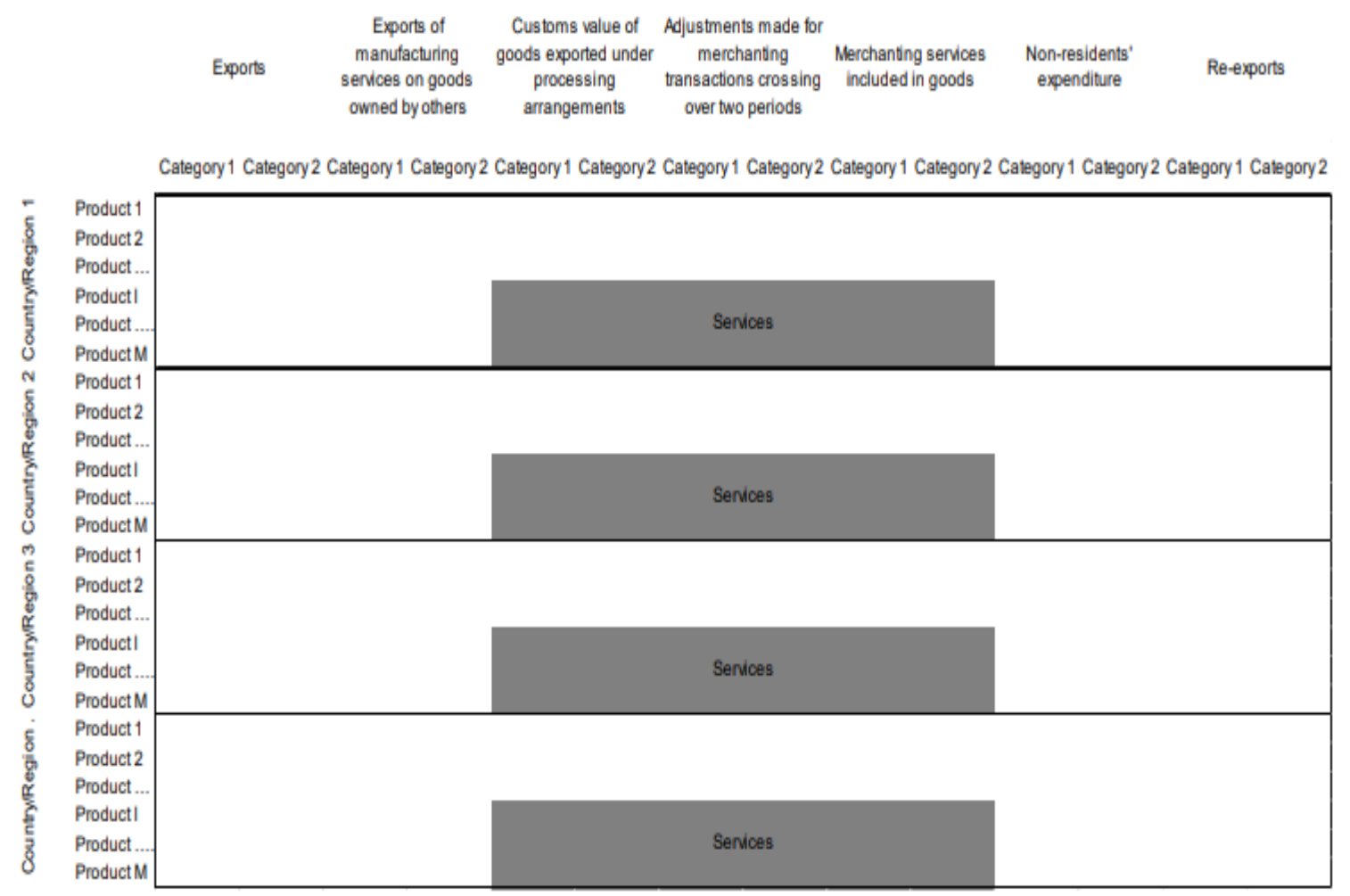

One final complementary extension is of considerable use relates to capital flow matrices. Many countries can produce estimates of gross fixed capital formation (plant and machinery, intellectual property) by activity at a relatively aggregated product level and rarely at the level of product detail provided in conventional supply-use tables. This is a significant statistical gap. It necessarily hinders the development of high-quality KLEMS type statistics as, by definition, it requires relatively aggregated measures of capital stock derived typically via the perpetual inventory method. But it also limits extensions in the domain of TiVA type statistics. Nonetheless, it is also important to note that there is no need to break down or provide additional extensions of all activities in the same way. After all, how countries define the categories of firms necessarily depends on the quality and availability of complementary information. 
Figure 4: Extended Supply-Use Tables (Activity breakdown) for Investment and Capital Stock
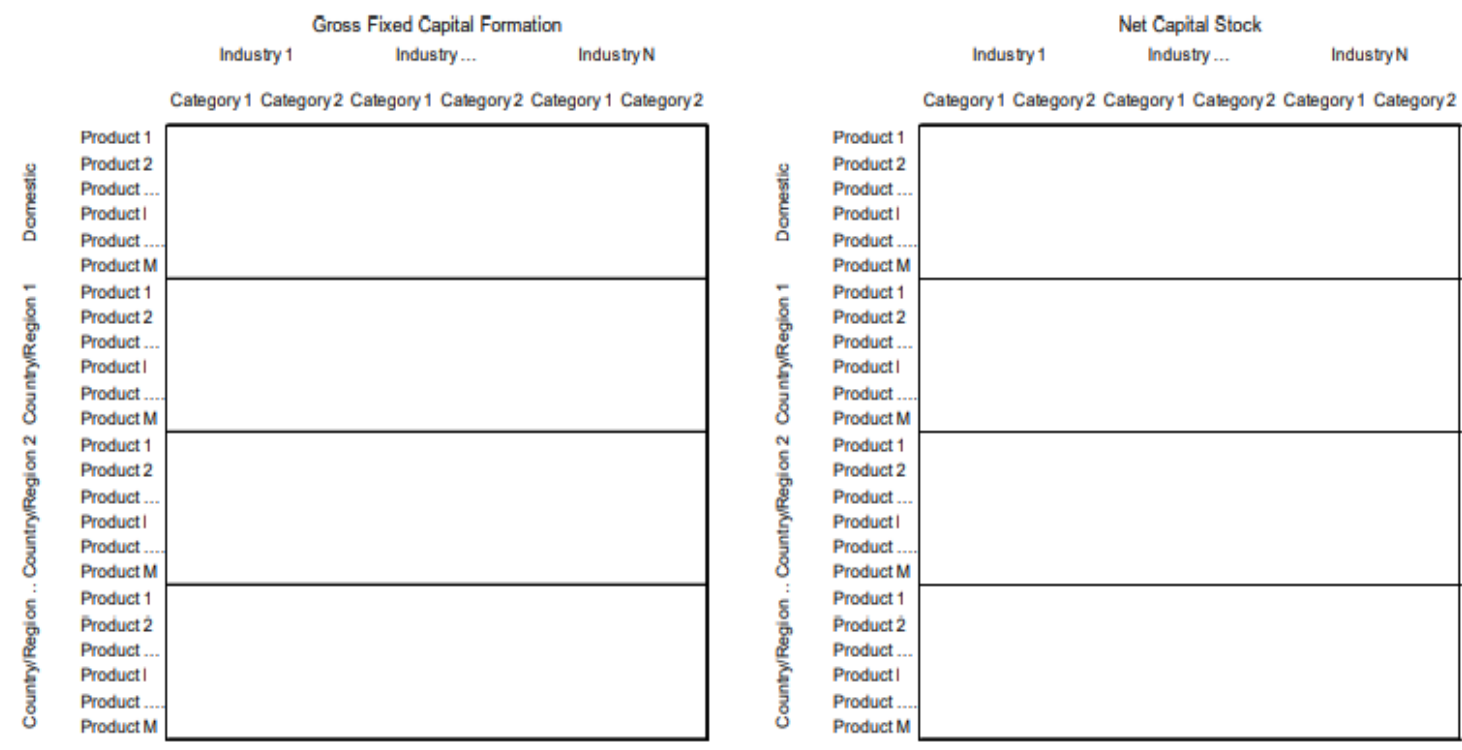

\section{Capitalizing on Customs registers}

Customs registers are the rich sources of imports and exports by enterprises. In many countries, complementary information is available on the enterprises that operate within. Customs registers can provide an excellent source for extended SUTs to link the statistical units recorded corresponding to the core statistical business register. It is the basis of the Trade by Enterprise Characteristics datasets for recent years across many countries. The following data are available by size class and industry through a simple matching exercise: Number of exporting and importing firms, exporting values of exporting firms, direct imports by products, direct imports by exporting firms. More recently, several countries have started to collect information breaking flows by ownership (foreign/domestic) too.

This linking exercise can provide the building blocks for creating new aggregations of firms within supply-use tables breaking down into some combinations of direct/no direct Imports and exports. Regarding heterogeneity of production functions, with respect to measuring facets of globalization, such groupings could significantly improve the quality of estimates as they broadly define firm aggregations based on one of the key target indicators of globalization: import content of a firm's exports. In constructing conventional supply-use tables national compilers currently produce aggregations on activity information alone. By using the above additional disaggregation, it is, at least in theory, a trivial exercise to produce extended supplyuse tables by trading status.

However, there are some complicating features to note down. The first relates to the statistical unit. The statistical unit is not always the same in the business register and the customs register. It is not necessarily the same as the unit used in constructing conventional national supply-use tables. Customs registers often, but not exclusively, capture units in line (or close to) with the enterprise concept. Whereas the statistical unit used in statistical business registers is often a 
legal unit and the unit used for conventional SUTs is the establishment. It is important to use a common unit or appropriate link (making apportionment methods) across the various datasets. It is relatively trivial exercise as the unit used is the same across all domains in many countries. But if the units are not the same and reliable apportionment are onerous, then it seems preferable to select the highest common denominator (the enterprise) as the basis for the units across three domains.

Another complication with respect to the use of customs registers in compiling extended SUTs relates to the notion of exporting and importing firms. In most countries, the distribution firms (wholesale and retailers) make a significant share of total imports and exports. But the conventional SUTs show these firms as facilitators of import and exports, not the actual consumer and producer. If we can establish that the distribution firm is affiliated to an upstream producer, then we can allocate the import and export of the affiliated distribution firm to its affiliated consuming or producing partner. However, we need a careful interpretation of terminology for a significant share of overall exports of a particular product by distributors if we cannot make the links. In this case, countries should refer to firms as direct exporters or highly export oriented. These same principles are necessary for imports also. This precise terminology concerns scale. The share of firms not engaged in trade are rarely insignificant, and moreover a significant share of these forms export either very little or a small percentage of their output.

An aggregation of firms purely around the concept of whether they export or import may be too simple to deliver a significant improvement in homogeneity and policy relevant indicators like the import content of exports. In this context, a practical approach is to introduce a size threshold for differentiating size of the firm (share of output) to export. One strength of this approach is that it can significantly reduce compilation burdens that may arise when we undertake full linking and full disaggregation of activities. Although the confidentiality issues emerge for the higher inclusion threshold, but the point is to introduce significant improvements in homogeneity through looking at only smaller grouping of firms or targeted activities. This introduction of threshold is most important for developing economies where compilation burdens may rapidly become onerous and exports are around a handful of core activities. Another reason of this approach is the defining features of GVCs showing the high correlation between direct imports and direct exports. This means that a simpler approach that focuses on a core set of large exporters and activities is also likely to capture the desired homogeneity obtained through additional aggregations of importers (moreover in most countries most exporters import).

\section{Structural business statistics for a size class dimension}

Another area of significant policy interest and a long-standing source of heterogeneity relates to the sizes of the firms. It is well-known fact that larger firms are more capital intensive than smaller firms and that they can capitalize on economies of scale. But it is also true that these economies of scale also manifest themselves in a trade context. Larger firms are more readily able to accommodate any fixed costs involved in international trade, and it is perhaps no coincidence that in most countries a significantly smaller share of smaller firms engages in international trade than larger firms, certainly with respect to exports. 
In practice, it is a relatively trivial exercise to create breakdowns of activities into size class dimensions. Statistical business registers nearly always include these dimensions and together with the activity code, they form one of the most important pillars of survey sample design. However, there is considerable interest in respect of globalization concerns about the degree of integration of various categories of firms within GVCs. For those countries where survey or administrative sources reveal the share of output for export, one relatively simple innovation is to include this information as an additional row in SUT.

There are more things to do. We can explore by countries concerns links at the detailed industry activity level with detailed merchandise trade customs data. Such a matching exercise may reveal those exports of detailed 6- to 8-digit HS (Harmonized System) products are from the production processes by certain categories of firms in terms of large, medium, or small. If more than one category of firm size is responsible for production, we can use proportionality assumptions. But it is not perfect for number of reasons, because there is perhaps a higher probability that larger firms will account for a disproportionate share. Therefore, the impact of the assumption is likely to be less if we conduct the matching at a relatively detailed product. This approach provides an ability to split the conventional export column in SUTs into categories of exporters by size class. It also provides an ability to create further extension to include a breakdown by destination. This is of relevance as the evidence points clearly to smaller firms exporting disproportionately within neighbouring countries and with countries where trade agreements exist compared to larger firms.

One avenue can greatly improve the quality of information on imports and exports broken down by size class is to link SBS data to customs registers, by adopting the same linking methods we are discussing. We should be careful in compilation as exports and imports included in customs registers are often in record by distributors. But by combining detailed HS data, SBS data, and TEC-type statistics, the quality of this exercise will rise through the development of breakdowns showing origin country of imports and the destination country of exports.

\section{FDI and FATS data for an Ownership dimension}

Arguably one of the most useful dimensions for constructing extended SUTs concerns breakdowns by ownership structures of Foreign Owned Affiliates (FA), Domestic MNEs (DM) with affiliates abroad, and Domestic Firms (DF) with no foreign affiliates. Generally, Foreign owned firms and multinationals shape GVCs. Foreign owned affiliates are responsible for considerable shares of overall activity and in particular trade, despite their relatively limited number, with a much higher orientation towards international than their purely domestic counterparts. A focus on this small number of firms could therefore prove to be very effective channel for developing extended supply-use tables.

But a focus on ownership dimensions is also crucial for policy reasons. Thus far the TiVA database has been able to provide insights into GVC policy making by creating a narrative around trade. However, it is important to create a trade-investment story for understanding the nature of GVCs and their drivers. MNEs have been important drivers of the growth in GVCs with estimates pointing around three quarters of total international trade. Moreover, the share 
of value added generated by foreign affiliates approaches around half of all business sector value added in some countries.

Value added essentially reflects two main components (with taxes and subsidies on production) - one is operating surplus including mixed income or compensation for capital, and another is compensation for employment. Although the latter component largely reflects the direct benefits that accrue and stick within the economy through production, the case is not so clear for the former component because of foreign affiliates. In perfect markets, foreign affiliates generate the operating surplus equivalent to the return on produced tangible and intangible capital and non-produced assets used in production. While the national accounts of countries attribute the ownership of this capital to the affiliated enterprise, the ultimate beneficiary of the operating surplus is not necessarily the affiliate but its parent. This has raised question, often in emerging economies but also in developed economies, about the actual benefits of foreign MNEs to host economy. Indeed, more recently it has begun to raise questions about the meaningfulness of GDP itself as a tool for macro-economic policy making.

In this regard, transactions in intangible assets recognised in the System of National Accounts as produced (such as research and development, software, etc.), non-produced (such as brands), and other knowledge-based capital (such as organisational capital of management competencies) are particularly important. Often international trade in services statistics record payments for the use of these produced ad non-produced assets as purchases (intermediate consumption) by one affiliated enterprise from another. But sometimes implicitly they are under record of primary income payments (such as investment income, or reinvested earnings in the Balance of payments). In the first case, as the value added generated through ownership of the asset appears on the accounts of the affiliate that owns it, the value added of the affiliate using the assets is lower. Whereas in the second case, the value added of the affiliate using the asset is higher (as there is no intermediate consumption) with the ultimate beneficiary (the owning affiliate) recording no value added but instead receiving primary income from the using affiliate. In both cases, however, the ultimate income generated by the asset ends up on the books of the owner (at least in theory, as even the very notion of the ultimate owner is a complex issue).

Furthermore, the distinction between the two above scenarios is often in doubt by the ability of the statistical information system to record the flows and transfer pricing and tax incentives of MNEs. TiVA estimates consistently reflect the way these flows recorded in a country's national accounts representing the accurate share of a country's overall value added in export. But they do not entirely reflect how countries benefits from GVCs, because part of the valueadded repatriates to the parent enterprise and does not remain in the economy. As a result, the policy focus has switched from GDP to GNI or new accounting concepts. This is not an issue singularly related to knowledge-based assets. Transfer pricing is also prevalent in transactions related to goods. Moreover, a significant income flows generated by an affiliate may repatriate to parents as interest payments.

Measuring these flows can provide an important narrative on the links between GVCs and foreign direct investment. It can also estimate to overcome differences in statistical practices for recording trade in knowledge-based assets. This requires more detailed data beyond the current industry-level information in the TiVA database incorporating additional breakdowns of firms with ownership. Statistical tools to create these breakdowns do currently exist in many 
countries, those with good quality FDI data and those producing FATS data. Definitional issues are of course of relevance here. FDI data captures associate firms (where foreign parents hold between $10-50 \%$ of the company's capital) and subsidiaries (50\% and over). While FATS data capture only subsidiaries. But we can develop breakdowns in line with national circumstances and data availability following either FDI or FATS definitions for coherent accounting frameworks. In fact, we have discussed that a breakdown by ownership structures would also provide an ideal basis for integrated and detailed balance of payments and national accounts.

\section{Extending the core production accounts to the distribution of income account and other macroeconomic variables}

One of the fundamental drivers behind the development of Extended Supply-Use tables is to provide the accounting framework for coherent and integrated international accounts. Currently, within the SNA and BPM6, there is no requirement to provide an activity breakdown of core economic variables. Only the transactions relating to the distribution of income are in compilation based on SNA institutional sectors. One important reflection in this respect concerns the nature of the statistical unit. Here the statistical unit is the establishment for such extension of SUTs. It requires many transactions for the distribution of income account. The extensions also include other macroeconomic variables chiefly relating to a suite of employment variables. These extensions relate to conventional measures of employment headcounts, such as persons engaged, employees, hours worked, and additional information on occupations. Occupational data is a key tool to understanding globalization for providing an easily interpretable link to skills, data mechanisms to analyze heterogeneity across firms, and the manner of their integration into GVCs. It is true that firms grouped within certain activities may find themselves engaged in different tasks in the value chain, even if they are allocated to the same sector. Therefore, the conventional activity-based data may mask such heterogeneity. At least, occupational data can provide some general scope to better understand these differences and their implication for growth and employment.

The potential to go further in this regard is significant. It is possible to consider additional extensions that create partition among workers based on wage and salary cohorts, productivity cohorts or skills. These are also key to understanding the distributional impacts of globalization. However, it is also possible to develop these additional insights in an ad-hoc manner. 
Figure 5: Property income and other macro-economic extensions

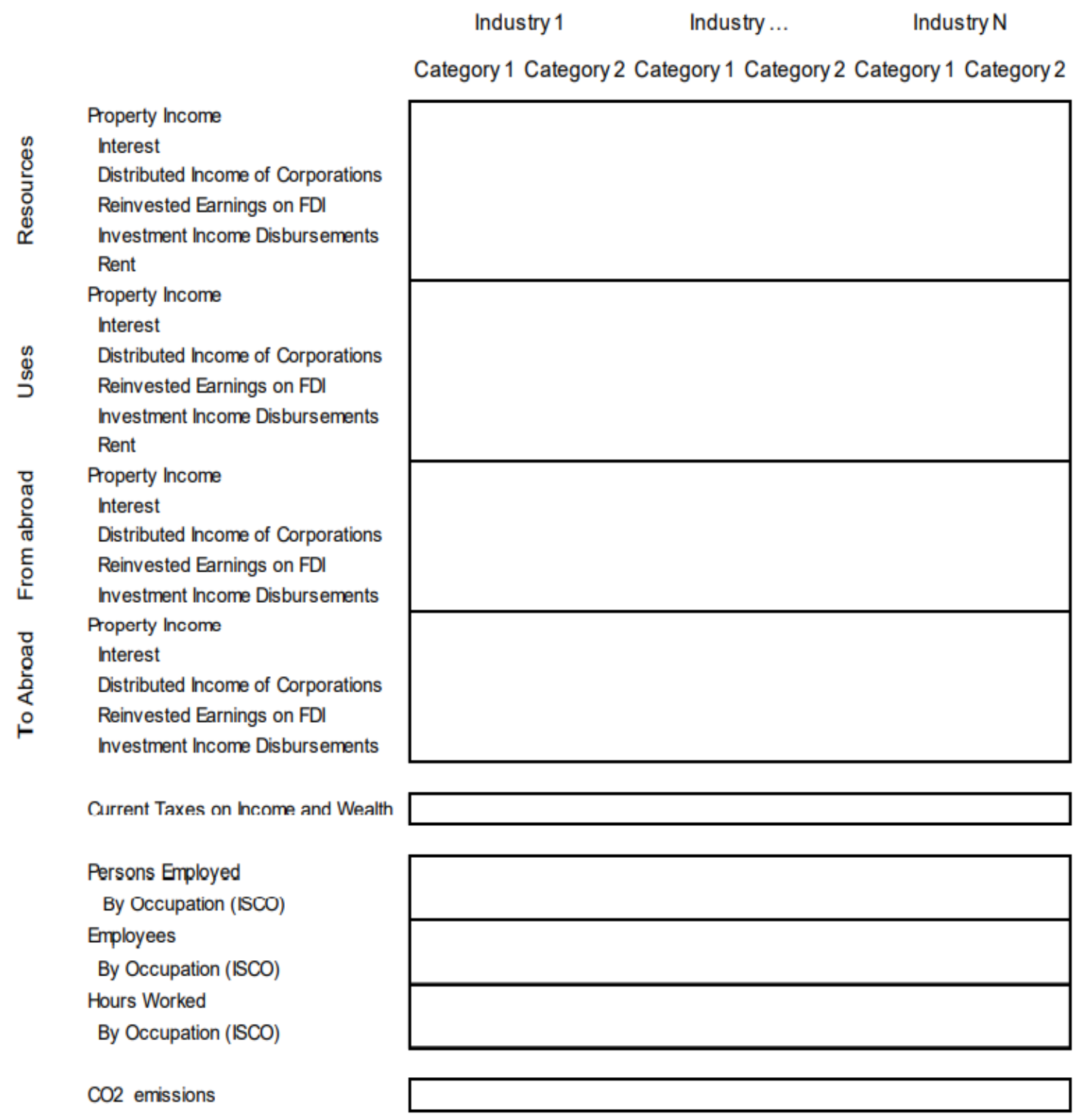

It presents an overview of the extensions considered. It is important to note that not all items are necessary. Extensions, in this respect, should not be the "all or nothing" choice. The objective is to show a set of seamless accounts that users take from the production account through the distribution of income accounts. It is non-trivial to do this at the level of the total economy. But it may be easy as a key focus to do this for cross-border flows with respect to reinvested earnings and perhaps debt interest. The additional note in the set of extensions below are the items on current taxes on income and wealth and $\mathrm{CO} 2$ emissions, which are both of policy interest. We get the first one through the breakdown of activities by ownership, as there is a long-standing and growing interest in understanding whether multinationals can generate significant advantages through fiscal optimization and where there are currently considerable information gaps. 


\section{Breaking down SUT rows by category of producers}

Perhaps the most complicated feature of full-blown extended supply-use tables is breakdowns of rows (products) by origin producer. It is of course relatively trivial to provide such a breakdown on the supply side but doing so by category of consumer is significantly more complex. This complexity necessarily differs depending on the nature of the breakdown used for activities. Breakdowns by size class require that consumers are aware about their purchase of goods and/or services from a small, medium, or large enterprise. In some countries some scope to do this is available from VAT data, but this requires a level of access to firm-level data with compilation burden. However, the scope is to some extent less for the breakdowns that focus on the exporting status of firms. In fact, irrespective of the type of the breakdown used, the higher the export intensity of a category of firms the lower the impact of assumptions to allocate the residual non-exported output to domestic consumers.

The allocation of residuals (output minus exports) to remaining categories of users necessitate the use of some stylized assumption. It is not so dissimilar to the classic proportionality assumption used in constructing import flow tables. Some refinements are of course possible, but these may create circularities to keep in mind. There are some self-selecting facts that point to better integration of manufacturing SMEs in domestic value chains than service SMEs. Hence, we need to be careful in presenting results to users. There are some approaches to develop information on the scale of integration of SMEs within GVCs and regarding the scale of integration of non-trading firms and purely domestic firms. The figure presents a full extended SUT with the requisite product breakdown. Note that there is no need for further breakdowns of import flow tables. 
Figure 6: Full Extended Supply-Use table
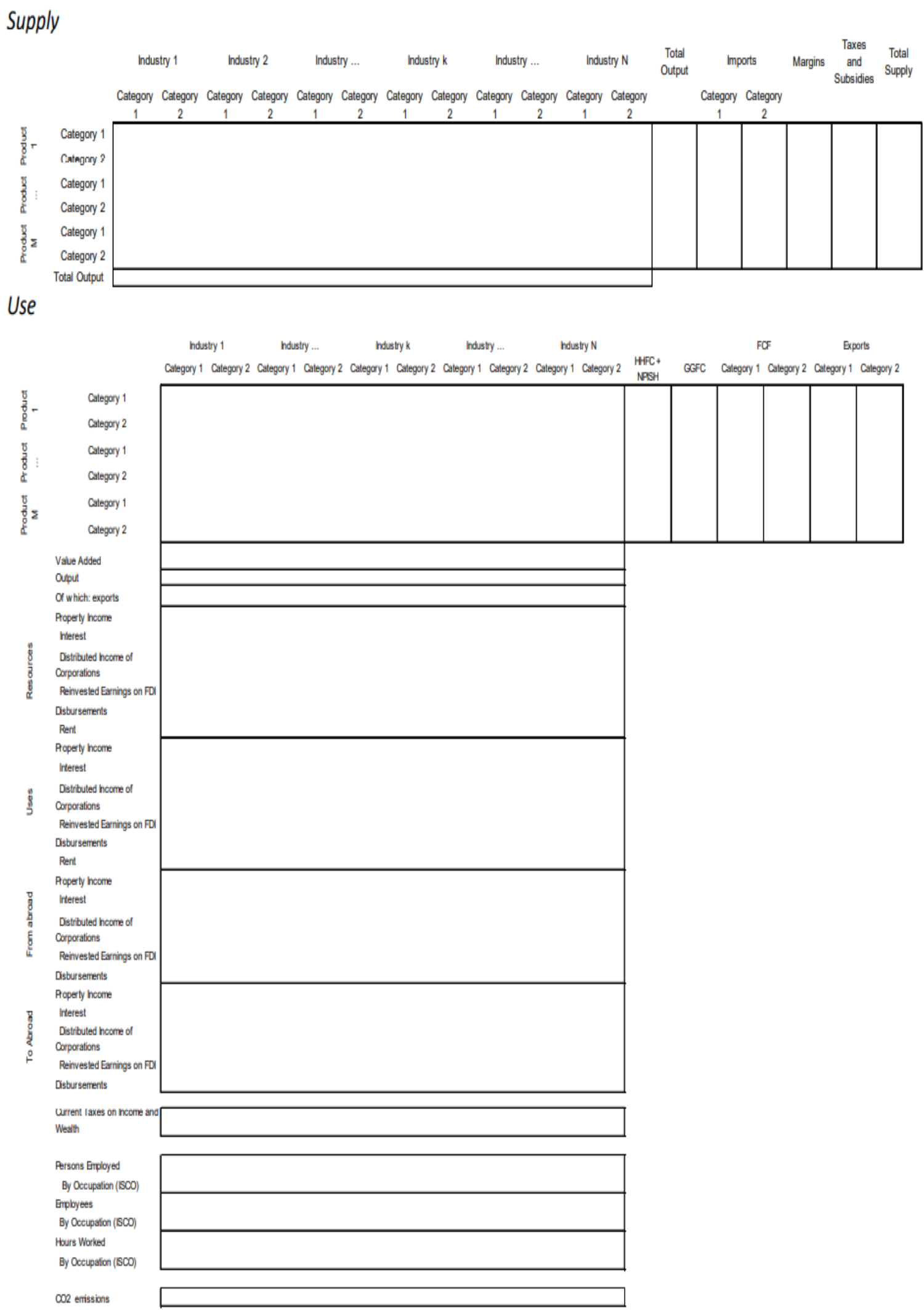


\section{Conclusion}

The statistical challenges of globalization are profound. We cannot rely solely on national statistics to understand how economies work and how to create industrial policies focusing on competitiveness. It is necessary to see the whole. National statistics build pictures based on relationships between producers and consumers and the rest of the world. But these relationships, especially those with the rest of the world, have become increasingly more complex. There is an increasing need to consider global production within a global accounting framework. This implies a departure from the traditional role of international organizations as compilers of internationally comparable national statistics to bring together the national tables to create a global table.

TiVA estimates have been able to shed important light on our understanding of international trade and its relation to activity and competitiveness. These also recognize the importance of imports to exports, hidden costs of protectionism, benefits of trade liberalization, and immense contribution of services in manufacturing. But still, it is not the full picture. Because, there are some issues regarding the accurate recording of foreign affiliates in exports, repatriation of profits related to the use of produced and non-produced knowledge-based assets. Therefore, emergence of global value chains raises profound questions about the way we currently compile national statistics. There should be a synchronization about "national" and "world" between international organizations and national statistics institutions.

In other words, role of the rest of the world both as a source of demand and supplier of demand (role of multinationals) needs greater emphasis in the construction of national statistics. This requires a rethink how we currently aggregate firms within statistical information systems. We need to move beyond the classic aggregation based almost exclusively on industrial classification systems towards more meaningful aggregations that better reflect today's global factory. These considerations are also essential to better understand the organization of global production, how investment drives global value chains, and investment-led difficulties in interpreting trade flows as well as GDP.

Extended supply-use tables provide an effective tool to respond to these developments and growing needs. Certainly, the evidence suggests to review our long-standing assumptions concerning homogeneity of firms within industry classifications. The evidence also suggests to achieve an optimal level of aggregation in FATS and TEC data without any significant increase in compilation of reporting burden and confidentiality constraints. Supply-Use tables have become the conventional route for many countries to resolve issues ideally regarding coherent estimates of the national accounts, trade, and production. Extended Supply-Use tables can play a similar role in responding to globalization. 